\title{
ÍNDICE DE PEGAMENTO E PRECOCIDADE DE MUDAS DA VARIEDADE FB200 ENXERTADA EM DIFERENTES ESPÉCIES SILVESTRES E COMERCIAIS DE MARACUJAZEIRO ${ }^{1}$
}

\author{
JANAINA BATISTA LENZA², JOÃO PEDRO VALENTE³, \\ GIVANILDO RONCATTO ${ }^{4}$, LÉO ADRIANO CHIG $^{5}$
}

RESUMO- O maracujazeiro-amarelo (Passiflora edulis Sims.), principal Passifloracea cultivada no Brasil, vem registrando diminuição na longevidade, dos pomares ao longo dos anos, devido à incidência de pragas e doenças que atacam o seu sistema radicular. O objetivo deste trabalho foi comparar o índice de pegamento e a precocidade na emissão de gavinhas da variedade 'FB200' enxertada nos porta-enxertos $P$. edulis, $P$. quadrangularis, $P$. giberti, $P$. coccinea, $P$. alata, $P$. nitida e na variedade 'FB200'. O experimento foi realizado em viveiro sob telado (50\% de sombra), na Fazenda Experimental da FAMEV/UFMT. Os porta-enxertos e enxertos foram oriundos de sementes, do viveiro Flora Brasil (Araguari-MG), UNESP/Jaboticabal-SP, e coletados na região. O método de enxertia foi de fenda cheia utilizando-se de porta-enxertos com três folhas e altura de 15 a $30 \mathrm{~cm}$ até o ponto de enxertia. As mudas apresentavam, no momento da enxertia, 30 a 90 dias. O delineamento experimental foi o inteiramente casualizado, com sete tratamentos e três repetições, onde cada parcela foi formada por 15 mudas enxertadas. $O$ índice de pegamento e a emissão de gavinhas foram avaliados em intervalos quinzenais, até os 60 e 120 dias, respectivamente. As mudas do maracujazeiro 'FB200', enxertadas em Passiflora edulis, P. quadrangularis e 'FB200', apresentam o melhor índice de pegamento da enxertia e precocidade na emissão de gavinhas, estando aptas para serem levadas ao campo entre 30 a 120 dias após a enxertia.

Termos para indexação: porta-enxerto, pegamento, gavinhas, desenvolvimento de mudas.

\section{INDEX OF ESTABLISHMENT AND PRECOSITY IN SEEDLINGS OF 'FB200' GRAFTED IN DIFFERENT SPECIES OF PASSION FRUIT TREES}

\begin{abstract}
The yellow passion fruit tree (Passiflora edulis Sims.) main Passifloracea cultivated in Brazil, has been registering reduction in the longevity of the orchards throughout the years, due to the incidence of illnesses that attack its radicular system. The challenge is to search for mechanisms that make possible to extend the cycle of this culture. The objective of this work was to compare the index of establishment and precocity in the emission of tendril of the grafting variety 'FB200' in the rootstocks: P. edulis, P. quadrangularis, $P$. giberti, P. coccinea, P. alata, P. clear and in the variety 'FB200' (yellow passion fruit tree). The experiment was carried out in a nursery under fabric ( $50 \%$ of shade), in the Experimental Farm of the FAMEV/UFMT. The rootstock and grafting had been deriving of seeds, from Flora Brazil Nursery (Araguari-MG), UNESP/ Jaboticabal-SP and collected in the region. The grafting method was of full cleft grafting using rootstock with three leafs and height of 15 the $30 \mathrm{~cm}$ until the grafting point. The seedlings presented at the moment of the grafting, about 30 to 90 days. The experimental delineation was entirely randomized, with seven treatments and three repetitions, where each repetition was formed by 15 grafting seedlings. The index of establishment and the emission of tendril had been evaluated in biweekly intervals, until the 60 and 120 days respectively. Grafting seedlings of the passion fruit tree 'FB200' in Passiflora edulis, P. quadrangularis and in 'FB200', presents optimum index of establishment of the grafting and precocity in the emission of tendril, been apt to be led to the field after 30 to 120 days of grafting.
\end{abstract}

Index terms: grafting, rootstock, establishment, tendril, development of seedlings.

\footnotetext{
'(Trabalho 145-08). Recebido em: 09-06-2008. Aceito para publicação em: 14-05-2009.

${ }^{2}$ Bióloga, Esp. Genética e Evolução, Mestre em Agricultura Tropical, Docente da UNIC/IUNI - Avenida Beira Rio, bairro Jardim Europa, no 3.100 - Cep: 78065-480 Cuiabá, MT. lenzamaracuja@gmail.com

${ }^{3}$ Eng. ${ }^{\circ}$ Agrônomo, MsC. Dr. Prof. Dep. de Fitotecnica e Fitosanidade UFMT/FAMEV -Faculdade de Agronomia e Medicina Veterinária Av. Fernando Correa s/n Boa Esperança Cuiabá 78.060-900, e-mail: jdfac@terra.com.br

${ }^{4}$ Eng. ${ }^{\circ}$ Agrônomo, Msc. Dr. Pesquisador Bosista DCR. FAPEMAT/UFMT/CNPq. UFMT/FAMEV -Faculdade de Agronomia e Medicina Veterinária Av. Fernando Correa s/n Boa Esperança Cuiabá 78.060-900, e-mail: givanildoroncatto@gmail.com

${ }^{5}$ Eng. ${ }^{\circ}$ Agrônomo, Mestre em Agricultura Tropical, FAMEV/UFMT. Av. Fernando Correa s/n, CEP 78.060-900, Cuiabá, MT. Fone: (65) 615-8616; leochig@gmail.com
} 


\section{INTRODUÇÃO}

É conhecida a liderança mundial do Brasil na produção de frutas in natura, o que é Isto é favorecido pelas condições ambientais. Entretanto, quando pensamos nas exportações o País não tem utilizado este potencial, visto que ocupa apenas o $12^{\circ}$ lugar nas exportações mundiais (Fachinello et al., 1996).

O Brasil é responsável por cerca de $90 \%$ da produção mundial de maracujá, segundo Silva et al. (2005), produzindo aproximadamente meio milhão de toneladas destacando-se como uma das principais frutíferas cultivadas no País. O maracujazeiro- amarelo (P. edulis f. flavicarpa Degener) é a espécie de maior representatividade nos cultivos, tendo 95\% da área plantada. Os principais Estados produtores são Bahia, São Paulo, Sergipe, Espírito Santo, Pará e Minas Gerais (IBGE, 2007).O maracujazeiro pode ser propagado por sementes, bem como por estaquia e enxertia (RUGGIERO \& CORRÊA, 1980). Mas a forma de propagação comercial ainda é a sexuada.

No entanto, a propagação vegetativa constitui-se em uma possibilidade de avanço sob o ponto de vista da multiplicação de plantas selecionadas, para a produção em escala de frutos uniformes, tolerantes ou resistentes a pragas e doenças. O objetivo do trabalho foi de avaliar diferentes espécies de maracujazeiro como da para a variedade comercial FB200.

\section{MATERIAL E MÉTODOS}

O experimento foi realizado em viveiro telado (50\% de sombra), da Fazenda Experimental da FAMEV/UFMT, entre os meses de fevereiro e junho/2006. A Fazenda está localizada em Santo Antônio do Leverger/MT, situada a $30 \mathrm{~km}$ de Cuiabá, latitude $15^{\circ} 47^{\prime} 11^{\prime} \mathrm{S}$, longitude $56^{\circ} 04^{\prime} 17^{\prime \prime} \mathrm{W}$ e altitude de $140 \mathrm{~m}$. O clima da região é classificado conforme Köeppen, como Aw ou Tropical de Savana, com períodos distintos de secas e chuvas. A temperatura média anual fica em torno de $26^{\circ} \mathrm{C}$, precipitação média de $1.360 \mathrm{~mm}$, umidade relativa do ar de $66 \%$ (Miranda \& Amorim, 2000).

O método de enxertia utilizado foi do tipo fenda cheia, realizado acima da terceira folha e a uma altura variável, dependendo da espécie (15 a $30 \mathrm{~cm}$ de altura). As espécies e acessos utilizados como porta-enxertos foram: Passiflora edulis (acesso Guiratinga-MT), P. quadrangularis (acesso Cuiabá-MT), P. giberti (acesso Jaboticabal-SP), $P$. alata (acesso Aquidauana-MS), maracujazeiroamarelo ('FB 200'-Araguari-MG), P. nitida (acesso Santa Terezinha-MT), P. coccinea (Jaboticabal-SP). Utilizou-se como copa (enxerto) o maracujazeiro- amarelo ('FB200'-Araguari-MG).

As sementes, utilizadas para a produção dos porta-enxertos e do enxerto, foram previamente embebidas em água destilada por cerca de 24 horas, em seguida semeadas em tubetes de plástico $(25 \times 5 \mathrm{~cm})$ com substrato comercial Plantimax (carvão ativado e casca de pínus). As mudas foram transplantadas para saco de polietileno $(20 \times 30 \mathrm{~cm})$, com mistura de solo de superfície e esterco de curral bem curtido, na proporção de 5,25: 1 enriquecida com superfosfato simples $\left(5 \mathrm{~kg} \mathrm{~m}^{3}\right)$.

Quando as plantas apresentavam três a quatro folhas, aos 30 a 60 dias após a semeadura, dependendo da espécie, foi realizada a enxertia. Utilizouse uma lâmina de aço que, antes de operação, era mergulhada em água sanitária a $70 \%$, para evitar contaminações.

Os porta-enxertos foram decapitados a uma altura que variou de 15 a $30 \mathrm{~cm}$, em função da espécie/variedade, as quais apresentaram vigor inicial distinto. Fez-se uma incisão longitudinal de aproximadamente $2 \mathrm{~cm}$ no topo do porta-enxerto, para inserir o garfo (enxerto).

As folhas abaixo do ponto de enxertia, em número de 3 a 4 , foram mantidas nas plantas.

$\mathrm{O}$ enxerto foi retirado de plantas-matrizes jovens da variedade FB200, sendo que os ramos foram desfolhados, e os garfos, preparados com duas a três gemas com $10 \mathrm{~cm}$ de comprimento, sendo sua extremidade inferior cortada em forma de cunha, para possibilitar a sua inserção no porta-enxerto.

A enxertia pelo método de garfagem do tipo fenda cheia consistiu na inserção do garfo no porta-enxerto, previamente preparado. A região da união dos mesmos foi amarrada com fita plástica transparente (fitilho), e depois revestida com um saco plástico que acondicionou o enxerto e o portaenxerto, formando uma câmara úmida para possibilitar o aumento do metabolismo e acelerar a união dos materiais. Este saco plástico permaneceu de 15 a 20 dias após a enxertia

A partir do $15^{\circ}$ dia após a enxertia, foram feitas, em intervalos quinzenais, as avaliações do índice de pegamento e da emissão de gavinhas. Para determinar o índice de pegamento, contabilizaram-se as plantas a partir do momento que apresentavam início de brotação. A contagem de plantas com gavinhas foram realizadas considerando-se como emitidas as plantas com a estrutura da gavinha no início da fase de enovelamento. O índice de pegamento foi avaliado nos primeiros 60 dias, e a emissão de gavinhas, até 120 dias a partir da enxertia.

O delineamento experimental foi o inteiramente casualizado, com sete tratamentos e três repe- 
tições, onde cada parcela foi formada por 15 mudas enxertadas, perfazendo-se um total de 45 plantas por tratamento. As avaliações foram feitas em diferentes épocas após a exertia. Análises de regressão foram avaliadas.

\section{RESULTADOS E DISCUSSÃO}

O índice de pegamento está representado na Figura 1, onde se observa que as mudas enxertadas em $P$. edulis e $P$. quadrangularis apresentaram 45 plantas pegas até os 60 dias, representando $100 \%$ das plantas enxertadas. Aliado a este excelente resultado observou-se que os materiais apresentaram desenvolvimento uniforme em relação ao diâmetro entre enxerto e porta-enxerto. Estes resultados estão de acordo com os obtidos por Nogueira Filho (2003) e Nogueira Filho et al. (2005), que conseguiram pegamento de $100 \%$ em diversas espécies nativas de maracujazeiro como o P. edulis f. flavicarpa, P. alata, $P$. giberti. Ressalta-se que estes autores utilizaram a técnica de enxertia hipocotiledonar, que é um tipo de enxertia em que se utilizam plântulas obtidas a partir de sementes. Silva et al. (2005) também conseguiram $100 \%$ de pegamento com a espécie $P$. alata como porta-enxerto do maracujazeiro-amarelo, utilizando a enxertia de mesa por garfagem ou borbulhia, considerando-se excelente pegamento.

Os resultados de pegamento da enxertia foram satisfatórios para $P$. alata apresentando $95 \%, P$. giberti com 93\%, 'FB200' com $92 \%$ e P. nitida com $90 \%$. O P. coccinea obteve o menor índice, com $85 \%$ de pegamento das plantas enxertadas. Estes resultados são melhores do que os obtidos por Nogueira Filho (2003) e Nogueira Filho et al. (2005) na espécie $P$. coccinea, conseguindo $72 \%$ de pegamento, e por Lima et al. (1999), que também utilizaram enxertia por garfagem em fenda cheia, em plantas jovens, alcançando $60 \%$ de pegamento nas espécies de maracujazeiro em estudo. Menezes (1990) e Menezes et al. (1994) conseguiram até $90 \%$ de pegamento nestas mesmas espécies de maracujazeiro. Ressalta-se que estes autores utilizaram metodologia muito próxima da utilizada no presente trabalho. Estes resultados devem-se a vários fatores, desde o aprimoramento da técnica até a afinidade dos materiais genéticos, como a utilização de variedade comercial para o maracujazeiro-amarelo e acessos regionais, que apresentavam-se aclimatados na região.

Para P. nítida, obtiveram-se $90 \%$ de pegamento, sendo este resultado considerado semelhante ao obtido por Chaves et al. (2004), que relataram ter obtido com $P$. nitida índices de pegamento da enxertia numa faixa compreendida entre 86,7 e $100 \%$. Estes resultados ocorreram quando as estacas foram enxertadas aos 40 e 55 dias após a sua coleta e plantio, mas esse índice diminuiu aos 70 dias para $60 \%$ de pegamento. Essa redução foi atribuída ao envelhecimento dos tecidos da estaca, que se tornaram mais lignificadas. Salienta-se que estes autores produziram porta-enxerto a partir de estacas, enquanto no presente trabalho os porta-enxertos foram de plantas jovens oriundas de semente.

Vale ressaltar a variação de espécies utilizadas como porta-enxertos e enxertos encontrados nas bibliografias. Também se verifica grande variação nos índices de pegamento encontrados na literatura, mesmo quando se utiliza o mesmo método de enxertia e a mesma combinação enxerto/porta-enxerto.

$\mathrm{Na}$ Figura 2, observam-se os dados referentes ao número de plantas com emissão de gavinhas. Pelo teste não paramétrico de Kolmogorov-Smirnov ( $\mathrm{p}$ $=10$ ), todos os materiais avaliados neste trabalho apresentaram distribuição normal, o que demonstra a consistência dos dados obtidos.

As gavinhas começaram a ser emitidas a partir de 30 dias para o 'FB200', $P$. edulis e $P$. quadrangularis. Aos 60; 100 e 120 dias, observouse a emissão de gavinhas em 33\%, 66\% e 100\%, respectivamente, demonstrando que estes materiais induziram maior precocidade à mudas A emissão de gavinhas é considerada como um indicador do ponto de plantio em campo, ou seja, quando as mudas emitem gavinhas estão aptas para serem levadas ao campo.

Por outro lado, as mudas enxertadas em $P$. giberti iniciaram a emissão de gavinhas aos 60 dias, $P$. alata aos 90 dias e nas espécies $P$. coccinea e $P$. nitida somente aos 105 dias. Ressalta-se que, aos 120 dias (termino das avaliações), 33\% das mudas enxertadas em $P$. giberti e $P$. alata, e $18 \%$ das mudas de $P$. nitida e $P$. coccinea haviam emitido gavinhas. Estes dados demonstram a necessidade de maior período de tempo para produção de mudas de maracujazeiros enxertadas, se forem utilizadas estas espécies como porta-enxerto.

Os resultados obtidos neste trabalho estão de acordo com os obtidos por Nogueira Filho (2003) e Nogueira filho et al. (2005), os quais observaram que as espécies $P$. giberti, $P$. nitida e $P$. coccinea, demoraram mais que a 'FB200' para atingir o ponto de plantio a campo. São José et al. (1991) e Lima et al. (1999) observaram rápido desenvolvimento e precocidade induzida pelo maracujazeiro-amarelo. Vale ressaltar que estes autores consideraram o ponto de plantio quando as mudas enxertadas atingiram altura mínima de $15 \mathrm{~cm}$. No entanto, a emissão de gavinhas pode ocorrer em diferentes alturas 
de plantas, constituindo-se como parâmetro mais confiável para se detectar o momento de as mudas serem levadas a campo.

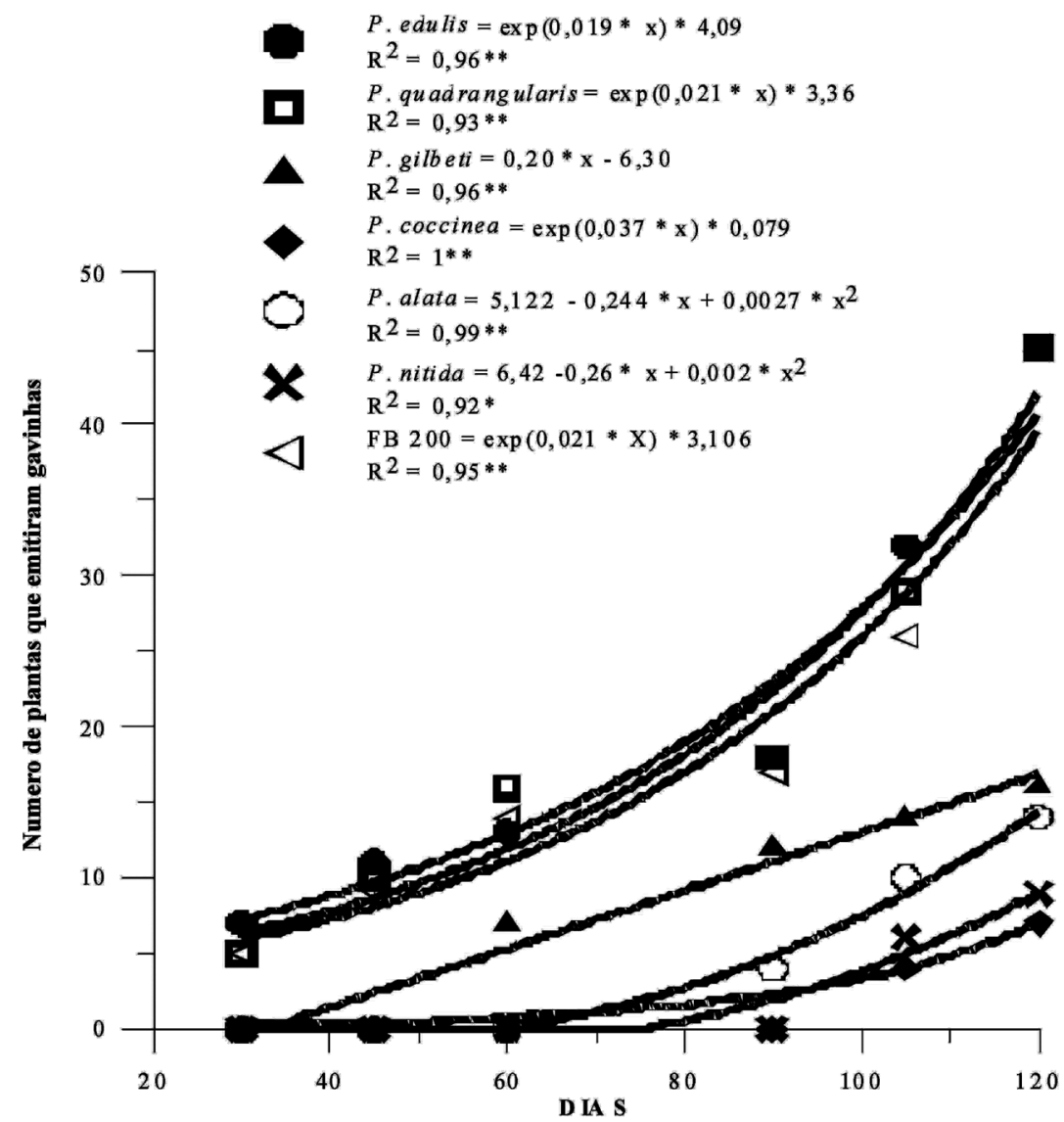

FIGURA 1 - Representação gráfica do número de plantas que brotaram até 60 dias após a enxertia da variedade FB200, enxertada em diferentes espécies e nela mesma. * Significativo a 5\%** Significativo a $1 \%$. 


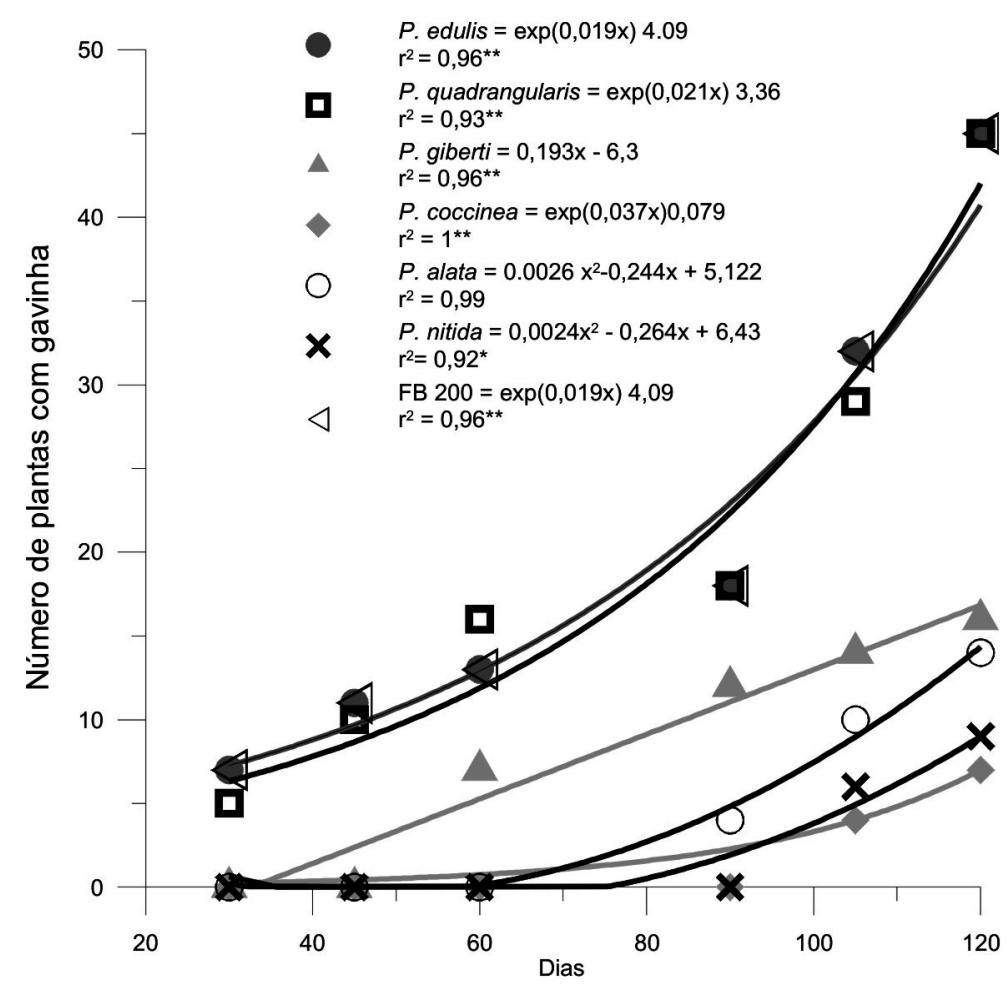

FIGURA 2 - Número de plantas que emitiram gavinhas até 120 dias após a execução da enxertia na variedade FB200, enxertada em diferentes espécies e nela mesma. * Significativo a $5 \% * *$ Significativo a $1 \%$.

\section{CONCLUSÕES}

1-As mudas de maracujazeiro 'FB200', enxertadas em Passiflora edulis, P. quadrangularis e no 'FB200', apresentam alto índice de pegamento da enxertia e precocidade na emissão de gavinhas, estando aptas para serem levadas ao campo entre 30 a 120 dias após a enxertia.

2- As espécies $P$. nitida e $P$. coccínea, utilizadas como porta-enxerto, retardaram a emissão de gavinhas na variedade FB200.

\section{REFERÊNCIAS}

CHAVES, R. da C.; JUNQUEIRA, N. T. V.; MANICA, I.; PEIXOTO, J. R.; PEREIRA, A. V.; FIALHO, J. F. Enxertia de maracujazeiro-azedo em estacas herbáceas enraizadas de espécies de passifloras nativas. Revista Brasileira Fruticultura, Jaboticabal, v. 26, n. 1, p.120-3, 2004.
FACHINELLO, J.C.; NACHTIGAL, J.C.; KERSTEN, E. Fruticultura: fundamentos e práticas. Pelotas: Editora Universidade Federal de Pelotas, 1996. 311p.

iBGE - Instituto Brasileiro de Geografia e Estatística. Produção Agrícola Municipal. Maracujá. Brasília: Ministério do Planejamento, Orçamento e Gestão, 2007. Disponível em: $<$ http://www.sidra.ibge.gov.br/bda/tabela/protabl. $\operatorname{asp} ? \mathrm{z}=\mathrm{t} \& \mathrm{o}=10 \& \mathrm{i}=\mathrm{P}>$. Acesso em: 19 jan. 2007.

LIMA, A. de A.; CALDAS, R. C.; CUNHA, M. A.P.; SANTOS FILHO, H. P. Avaliação de porta-enxertos e tipos de enxertia para o maracujá-amarelo. Revista Brasileira de Fruticultura, Jaboticabal, v.21, n.3, p.318-321, 1999.

MENEZES, J. M. T. Seleção de porta-enxertos tolerantes à morte prematura de plantas para $P$. edulis Sims f. flavicarpa Deg. e comportamento de P. nitida H.B.K. na região de Jaboticabal. 1990. 73 f. Dissertação (Mestrado em Melhoramento Genético Vegetal) -Faculdade de Ciências Agrárias 
e Veterinárias, Universidade Estadual Paulista, Jaboticabal, 1990.

MENEZES, J. M. T.; OLIVEIRA, J. C.; RUGGIERO, C.; BANZATO, D. A. Avaliação da taxa de pegamento de enxertos de maracujá-amarelo sobre espécies tolerantes à "morte prematura de plantas". Científica, Jaboticabal, v.22, n.1, p.95-104, 1994.

MIRANDA, L.; AMORIM L. Mato Grosso: atlas geográficos. Cuiabá: Entrelinhas, 2000.

NOGUEIRA FILHO, G. C. Enxertia hipocotiledonar de maracujazeiro-amarelo em diferentes espécies de passifloras silvestres. 2003. 119 f. Tese (Doutorado em Agronomia) - Faculdade de Ciências Agrárias e Veterinárias, Universidade Estadual Paulista, Jaboticabal, 2003.

NOGUEIRA FILHO, G. C.; RONCATTO, G.; RUGGIERO, C.; OLIVEIRA, J.C.; MALHEIROS, E.B. Propagação vegetativa do maracujazeiro-conquista de novas adesões. In: FALEIRO, F.G.; JUNQUEIRA, N.T.V.; BRAGA, M.F. (Eds.). Maracujá: germoplasma e melhoramento genético. Planaltina-DF: Embrapa Cerrados, 2005. p. 340-358.
RUGGIERO, C.; CORRÊA, L. S. Implantação da cultura e propagação. In: RUGGIERO, C. Cultura do maracujazeiro. Jaboticabal: Faculdade de Ciências Agrárias e Veterinárias, UNESP, 1980. p.23-31.

SÃO JOSÉ, A. R. Propagação do maracujazeiro. In: SÃO JOSE, A. R.; FERREIRA, E.R.; VAZ, R. L. (Coord.). A cultura do maracujá no Brasil. Jaboticabal: FUNEP, 1991. p. 25-42.

SILVA, F. M.; CORREA, L. de S.; BOLIANI, A. C. ; SANTOS, P. C. dos. Enxertia de mesa de Passiflora edulis Sims f. flavicarpa Deg. sobre Passiflora alata Curtis, em ambiente de nebulização intermitente. Revista Brasileira de Fruticultura, Jaboticabal, v.27, n.1, p.98, 2005. 